\title{
“Single Phase NPC Inverter Controller with Integrated MPPT for PV Grid Connection"
}

17th International Conference on Sciences and Techniques of Automatic Control and Computer Engineering (STA), 2016, Sousse, Tunisia,

http://ieeexplore.ieee.org/document/7952025/

ISBN: 978-1-5090-3407-9

DOI 10.1109/STA.2016.7952025

This material is posted here with permission of the IEEE. Such permission of the IEEE does not in any way imply IEEE endorsement of any of Group of Energy and Power Electronics, University of Minho, products or services. Internal or personal use of this material is permitted. However, permission to reprint/republish this material for advertising or promotional purposes or for creating new collective works for resale or redistribution must be obtained from the IEEE by writing to pubs-permissions @ ieee.org. By choosing to view this document, you agree to all provisions of the copyright laws protecting it.

\section{(C) 2018 IEEE}




\title{
Single Phase NPC Inverter Controller with Integrated MPPT for PV Grid Connection
}

\author{
Manel Hlaili ${ }^{1}$, Hfaiedh Mechergui ${ }^{1}$, Henrique Gonçalves ${ }^{2}$, Bruno Exposto ${ }^{2}$, João L. Afonso ${ }^{2}$ \\ 1 - LISIER Research Laboratory - ENSIT University of Tunis - Tunis, Tunisia \\ 2 - ALGORITMI Research Centre - University of Minho - Guimarães, Portugal \\ hlaili_manel@yahoo.fr, hafidmecher@yahoo.com, \{henrique.goncalves, \\ bruno.exposto, joao.1.afonso\}@algoritmi.uminho.pt
}

\begin{abstract}
This paper presents a single-stage three-level Neutral Point Clamped (NPC) inverter for connection to the electrical power grid, with integrated Maximum Power Point Tracking (MPPT) algorithm to extract the maximum power available from solar photovoltaic (PV) panels. This single-stage topology is more compact than the traditional topology, it was chosen because with the proper control strategy. It is suitable to connect the PV panels to the power grid. The paper describes the design of a $5 \mathrm{~kW}$ NPC inverter for the interface of PV panels with the power grid, presenting the circuit parameters and the description of the control algorithms. A phase locked loop control is used to connect the inverter into the grid. Then, a proposed DC Link voltage control to regulate the input voltage of the inverter. Although an MPPT algorithm was used to optimize the energy extraction and the system efficiency. Inverter Output Current control to produce an output current (current injected in the power grid) with low Total Harmonic Distortion (THD) implemented in a DSP. Simulation and experimental results verify the correct operation of the proposed system, even with fluctuations in the solar radiation.
\end{abstract}

Keywords - Photovoltaic System; Maximum Power Point Tracking (MPPT); Neutral Point Clamped (NPC) Inverter; Phase-Locked Loop (PLL).

\section{INTRODUCTION}

As the population in the world increases, the renewable energy sources acquire growing importance due to the global energy demand. In the last years, global warming and energy policies have become a hot topic on the international agenda as countries are making an effort to reduce the greenhouse gas emissions.

Solar and wind energy sources have become very popular as result of the increasing research on new technologies, namely photovoltaic (PV) power generation technologies that are being widely studied. Despite the achieved developments in solar technologies further improvements can be done in order to lower their price, increase efficiency and maximize the energy extraction. In most cases, grid connected PV systems consist in the PV panels array and a power converter. Several topologies of converter can be adopted.
Transformerless solutions are the most commonly adopted because of the high performance in terms of efficiency, higher reliability, smaller size and weight, and lower price $[1,2]$. It exist different commercial inverters topologies used in PV systems [3]. For the H5 inverter which is commercialized by SMA. It is a classical H-bridge with an extra fifth switch in the positive bus of the DC-link. Moreover, the HERIC (Highly efficient and Reliable Inverter Concept) inverter is currently commercialized by Sunways. It is also derived from the classical H-bridge by adding a bypass leg in the AC side using two back-to-back IGBTs. Furthermore, the REFU inverter from Refusol also derived from H-bridge. It uses a half bridge within the AC side bypass and bypassable DC-DC converter [3]. All these inverters convert the two levels Hbridge inverter into a three level one for less output voltage stress. Somewhere else, the neutral point camped (NPC) inverter achieve the lower switch stress and can be used in both single phase and three phase inverters. In addition, NPC inverters topologies are of interest due to their lower output current total harmonic distortion (THD), the use of semiconductors in less stressing conditions and the lower switching frequencies [4].

The aim of this paper is to present the design and implementation of the proposed single-stage three-level Neutral Point Clamped (NPC) inverter system that is used to interface a PV system with the electrical grid. The topology of the inverter is analyzed and the proposed control techniques are explained.

\section{Neutral Point Clamped InVERTER}

The multilevel inverters can be divided in three main topologies: flying capacitor, cascaded H-bridge and diode clamped multilevel inverters [5]. Neutral Point Clamped (NPC) inverter topology is used in this paper as shown in Fig.1. This type of multilevel inverter has the advantages of being simpler and cheaper when compared with other topologies. Besides this, the voltage on the switching power semiconductors, is half of the DC-link voltage and the output voltage and current have reduced THD [6,7], with smaller passive filter requirements [7].

Due to the diodes connected to the neutral point $\mathrm{N}$, the voltage across the switching power semiconductors is $V_{D C} / 2$, 


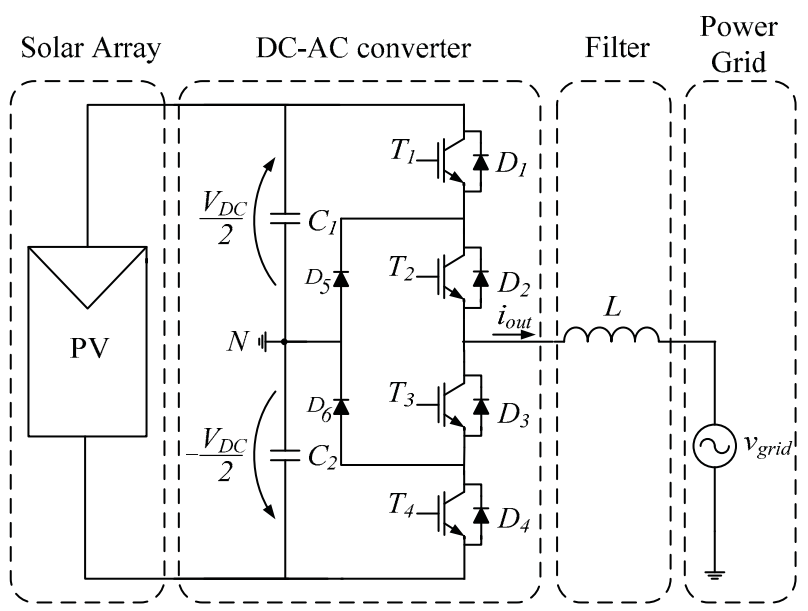

Figure 1. Implemented NPC converter for photovoltaic system.

and consequently the output voltage levels achievable in this topology are: $-V_{D C} / 2,0$ and $V_{D C} / 2$.

The switching states of the single-phase three levels NPC inverter are shown in table I. The switches $T_{1}$ and $T_{3}$, and $T_{2}$ and $T_{4}$, are switched complementary. The control of this inverter can be done using a PWM technique. To implement the PWM are used two superposed triangular carriers. Each carrier is connected to one of two groups of switches controlled complementarily. The positive part of the carrier fixes the switching state of $T_{1}$ and $T_{3}$ whereas the negative part controls $T_{2}$ and $T_{4}$.

For a good operation of the NPC inverter, the DC-link capacitors must have an equal voltage. Furthermore, when the ripple of the DC-link is high, the output current can be difficult to control. The ripple happens due to the charging and discharging of the DC-link capacitors. This paper used a single-stage topology without a DC-DC power converter between the panels and the NPC inverter, therefore the inverter control integrates the current control and the Maximum Power Point Tracking algorithm.

\section{THE PROPOSED NPC INVERTER CONTROL SYSTEM}

The control system of the proposed topology is composed by four main blocks:

-Phase-locked Loop (PLL) to synchronize the output voltage with the electrical power grid voltage;

-DC-link voltage regulation;

-Maximum Power Point Tracking (MPPT) control to impose the reference current to be injected in the grid;

TABle I. Switching States of A Single Phase Three LeVel NPC INVERTER

\begin{tabular}{|l|c|c|c|}
\hline $\begin{array}{c}\text { Output } \\
\text { voltage }\end{array}$ & Switches on & Output current & Current path \\
\hline \multirow{2}{*}{$V_{D C} / 2$} & \multirow{2}{*}{$T_{1}$ and $T_{2}$} & $i_{\text {out }}>0$ & $T_{1}, T_{2}$ \\
\hline \multirow{2}{*}{0} & \multirow{2}{*}{$T_{2}$ and $T_{3}$} & $i_{\text {out }}<0$ & $D_{1}, D_{2}$ \\
\cline { 3 - 4 } & & $i_{\text {out }}>0$ & $D_{5}, T_{2}$ \\
\hline \multirow{2}{*}{$-V_{D C} / 2$} & $T_{3}$ and $T_{4}$ & $i_{\text {out }}<0$ & $D_{6}, T_{3}$ \\
\cline { 3 - 4 } & $i_{\text {out }}>0$ & $D_{4}, D_{3}$ \\
\hline
\end{tabular}

-Inverter output current controller.

The block diagram of the implemented control system is shown in Fig.2.

The MPPT algorithm imposes the reference current to the current controller. This reference is added to the output of the DC-link voltage control. The resultant reference signal is multiplied by the unitary sinusoidal value from the PLL. The current control imposes the modulator reference waveform for the PWM block.

\section{A. Phase-Locked Loop}

To ensure the proper injection of current into the power grid is necessary to have a grid synchronization mechanism, i.e., to have information about the phase and frequency of the power grid voltage.

Different types of PLL have been developed and presented in literature [8,9]. In the proposed system an enhanced Phase-locked loop (E-PLL) was adapted to extract the fundamental components (phase angle and frequency) of the power grid voltage [10]. The E-PLL is less sensitive to power grid voltage distortion and is adapted to be used in practical applications with noisy conditions [11]. A block diagram of the E-PLL is shown in Fig.3.

The output signal of the E-PLL can be described as:

$$
v_{P L L}=V_{P L L} \sin \left(\varphi_{P L L}\right)
$$

This signal is in phase with the power grid voltage fundamental given by:

$$
v_{\text {grid }}=V_{\text {grid }} \sin \left(\varphi_{\text {grid }}\right)
$$

Where, $V_{\text {grid }}$ is the peak value of the power grid voltage, and $\varphi_{P L L}$ is the phase angle. The error between the power grid voltage and the output PLL signal can be expressed as:

$$
\varepsilon_{1}=V_{\text {grid }} \sin \left(\varphi_{\text {grid }}\right)-V_{P L L} \sin \left(\varphi_{P L L}\right)
$$

The output signal of the phase detector is:

$$
\varepsilon_{2}=\varepsilon_{1} \cos \left(\varphi_{P L L}\right)
$$

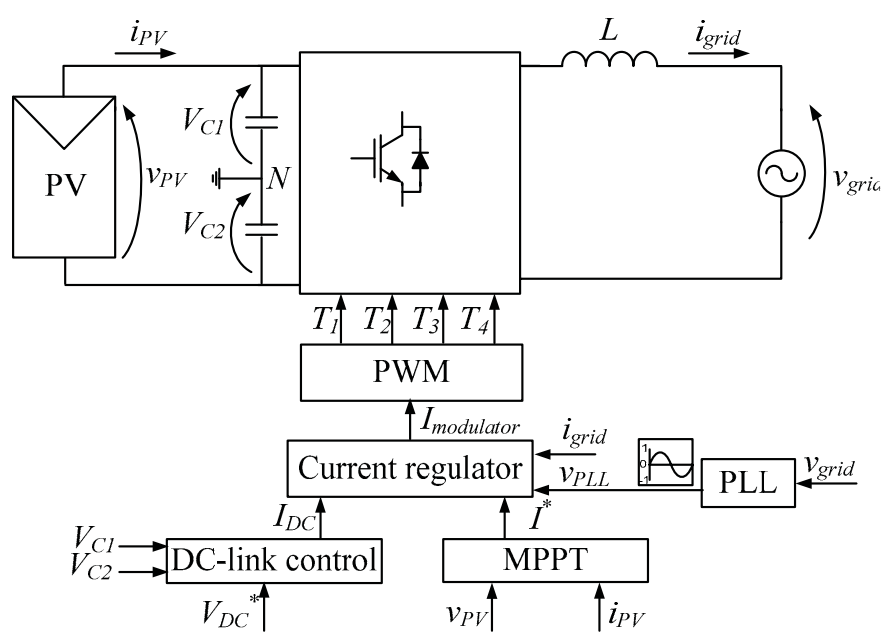

Figure 2. Block diagram of the NPC converter control system. 


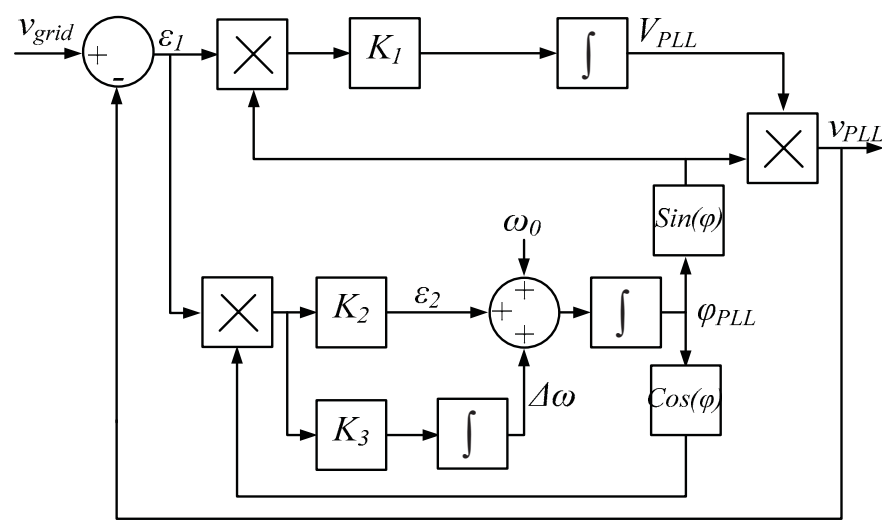

Figure 3. Block diagram of the E-PLL.

In steady state, $\varphi_{P L L}=\varphi_{\text {grid }}$, and so:

$$
\varepsilon_{1}=v_{\text {grid }}-v_{P L L}=0
$$

The phase $\varphi_{P L L}$ that is estimated by the PLL will be the phase angle of the reference output current injected into the grid which is:

$$
i_{\text {ref }}{ }^{*}=i_{f}{ }^{*} \times \sin \left(\varphi_{P L L}\right)
$$

Where $i_{f}^{*}$ is the amplitude of the fundamental component of the reference current which is equal to:

$$
i_{f}^{*}=I^{*}+I_{D C}
$$

Where $I^{*}$ is the PV current reference given by the MPPT algorithm and $I_{D C}$ is the current reference given by the DClink regulation.

The constant $K_{l}$ adjusts the amplitude convergence of the grid while $K_{2}$ and $K_{3}$ adjust the frequency and phase convergence.

\section{B. Maximum Power Point Tracking MPPT}

The maximum power supplied by the photovoltaic panels is not stable in the same operating point, whereas it varies with the weather conditions, such as solar irradiation and temperature. To extract the maximum power is necessary to implement a MPPT algorithm that dynamically adjusts the extraction of the power. Several MPPT algorithms have been studied by different authors, namely: Perturb and Observe (P\&O), Fuzzy Logic, Neural Networks, Genetic Algorithm and Lagrange Multiplier [12-15]. In the proposed system was applied the Incremental Conductance algorithm in order to track the Maximum Power Point (MPP). The advantages of using this method are the higher efficiency and fast tracking of the MPP in comparison with other algorithms [16].

The incremental conductance method is based on the principle that the slope of the PV array power curve is zero at the MPP, so that $\Delta P / \Delta V=0$, with $P=V I$.

Considering that:

$$
\left\{\begin{array}{lll}
\Delta I / \Delta V=-I / V & \text { if } & P=\mathrm{MPP} \\
\Delta I / \Delta V>-I / V & \text { if } & P<\mathrm{MPP} \\
\Delta I / \Delta V<-I / V & \text { if } & P>\mathrm{MPP}
\end{array}\right.
$$

The MPP can be tracked by comparing the instantaneous conductance $I / V$ with the incremental conductance $\Delta I / \Delta V$.

The algorithm increments or decrements the reference until the condition $\Delta I / \Delta V=-I / V$ is achieved. Once the maximum power is reached, the operation of the PV array is maintained at this point. It is an effective algorithm and requires high sampling rates and fast calculations of the power slope [16]. It offers different advantages which are good tracking efficiency and automatic adjustment of the module operating voltage with no oscillations. Also, the response is improved and the control for the extracted power is optimized [17]. The implementation of this algorithm in the control unit was difficult and expensive, but with recent developments in microcontrollers it became more cost effective [18]. It lends itself well to DSP control, which can easily keep track of previous values of voltage and current [19].

\section{DC-link Voltage Control}

In order to ensure that the system does not become unusable, an optimized DC-link voltage equalization control, shown in Fig. 2 is proposed. The controller imposes an increment or a decrement value added to the current reference, so that the voltage of the capacitors is approximately equal. To control the DC-link voltages, is used a PI controller for each capacitor voltage regulation and a digital filter to $V_{C 1}$ and $V_{C 2}$. The reference voltage is given by:

$$
V_{D C}{ }^{*}=V_{C 1}+V_{C 2}
$$

The error is then calculated according to the polarity of the PLL reference (10). This proposed method ensures that the regulation of the DC-link voltage does not affect the output current waveform. The minimum DC-link capacitance leads to larger voltage ripples. Nevertheless, such ripples were found to be within acceptable limits to run the inverter and the output current distortion has an acceptable level given in interconnection standards (IEC, IEEE, etc...).

$$
e_{V}(t)=\left\{\begin{array}{lll}
\frac{V_{D C}{ }^{*}}{2}-V_{C 1 a v g} & \text { if } & v_{P L L}>0 \\
\frac{V_{D C}{ }^{*}}{2}-V_{C 2 a v g} & \text { if } & v_{P L L}<0
\end{array}\right.
$$

The PI algorithm can be expressed in the continuous time domain as:

$$
u_{V}(t)=K_{p} e_{V}(t)+K_{i} \int_{\tau=0}^{t} e_{V}(\tau) d \tau
$$

The control is implemented in a DSP, therefore the PI controller must be implemented in discrete time. Considering the integration method of Forward Euler the PI can be expressed as:

$$
u_{V}(k)=K_{p} e_{V}(k)+K_{i} T_{s}\left[e_{V}(k)+e_{V}(k-1)\right]
$$

Where $T_{s}=1 / f_{s}$, with switching frequency $f_{s}=32 \mathrm{kHz}$.

\section{Current Control}

To connect the inverter into the power grid, is necessary to control the output current so that the power can flow from the 
inverter to the power grid. The performance of the inverters connected to the grid in terms of THD current (Total Harmonic Distortion) depends largely on the control strategy applied. thus, it exists in the literature different types of control such as predictive, hysteresis, periodic sampling, resonant controller and PI current control [20,21]. This paper presents the PI current controller because it is the most common and widely used type of controller, and because of its simplicity. It consists in comparing the output current of the inverter with the reference current that is imposed by the other parts of the control system.

The reference current is given by:

$$
i_{\text {ref }}{ }^{*}=u_{V}(t)+I^{*}
$$

The error can be expressed as:

$$
e_{I}(t)=i_{\text {ref }}{ }^{*}-i_{\text {grid }}
$$

The PI algorithm can be expressed in the continuous time domain as:

$$
u_{I}(t)=K_{p} e_{I}(t)+K_{i} \int_{\tau=0}^{t} e_{I}(\tau) d \tau
$$

Considering the backward Euler integration method the PI control can be expressed as:

$$
u_{I}(k)=K_{p} e_{I}(k)+K_{i} T_{s}\left[e_{I}(k)+e_{I}(k-1)\right]
$$

Where $T_{s}=1 / f_{s}$ with $f_{s}=32 \mathrm{kHz}$.

\section{Simulations Results}

In order to obtain a good characterization of the proposed topology, simulations were performed using PSIM software. The system was simulated under different operating conditions, in steady state and during transient state caused by solar radiation variations. All of aforementioned control loops (PLL, MPPT, DC-link and current control) were implemented using the programming language $\mathrm{C}$. This approach gives to the simulations a behavior that is similar to the practical application since the algorithms implementations are almost the same. The simulated algorithms can be easily directly exported to a DSP.

The inverter was designed to have a nominal power of

TABLE II. CIRCUIT PARAMETERS

\begin{tabular}{|l|l|l|}
\hline Parameters & Value & Units \\
\hline Number of panels in series & 23 & -- \\
\hline Series resistance & 0.0065 & $\Omega$ \\
\hline Shunt resistance & 1000 & $\Omega$ \\
\hline Short circuit current & 7.74 & $\mathrm{~A}$ \\
\hline Open circuit voltage & 991.3 & $\mathrm{~V}$ \\
\hline Maximum power & 5750 & $\mathrm{~W}$ \\
\hline Capacitors $\left(C_{I}\right.$ and $\left.C_{2}\right)$ & 470 & $\mu \mathrm{F}$ \\
\hline Inductance $(L)$ & 5 & $\mathrm{mH}$ \\
\hline Power grid voltage $(\mathrm{rms})$ & 230 & $\mathrm{~V}$ \\
\hline Power grid frequency & 50 & $\mathrm{~Hz}$ \\
\hline Power grid inductance & 100 & $\mu \mathrm{H}$ \\
\hline Power grid resistance & 0.03 & $\Omega$ \\
\hline
\end{tabular}

$5.7 \mathrm{~kW}$. All the circuit parameters are presented in table II.

The $L$ filter was designed to reduce the current distortion caused by the high switching frequencies of the IGBTs which is equal to $16 \mathrm{KHz}$. A sinusoidal pulse-width modulation SPWM was used to control the power semiconductors switching.

Fig.4 shows the synchronization of the PLL with the power grid voltage. When the system reaches the permanent state, the PI control output will be zero and the output of the integrator will vary between 0 and $2 \pi$.

In Fig.5 are presented the output current, voltage and
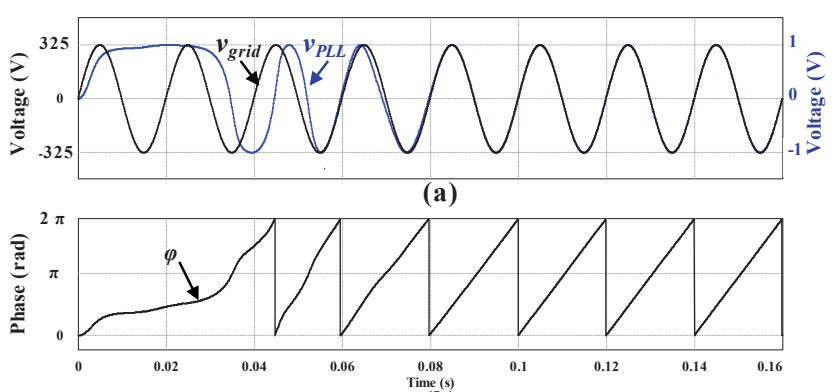

(b)

Figure 4. Block diagram of the E-PLL.
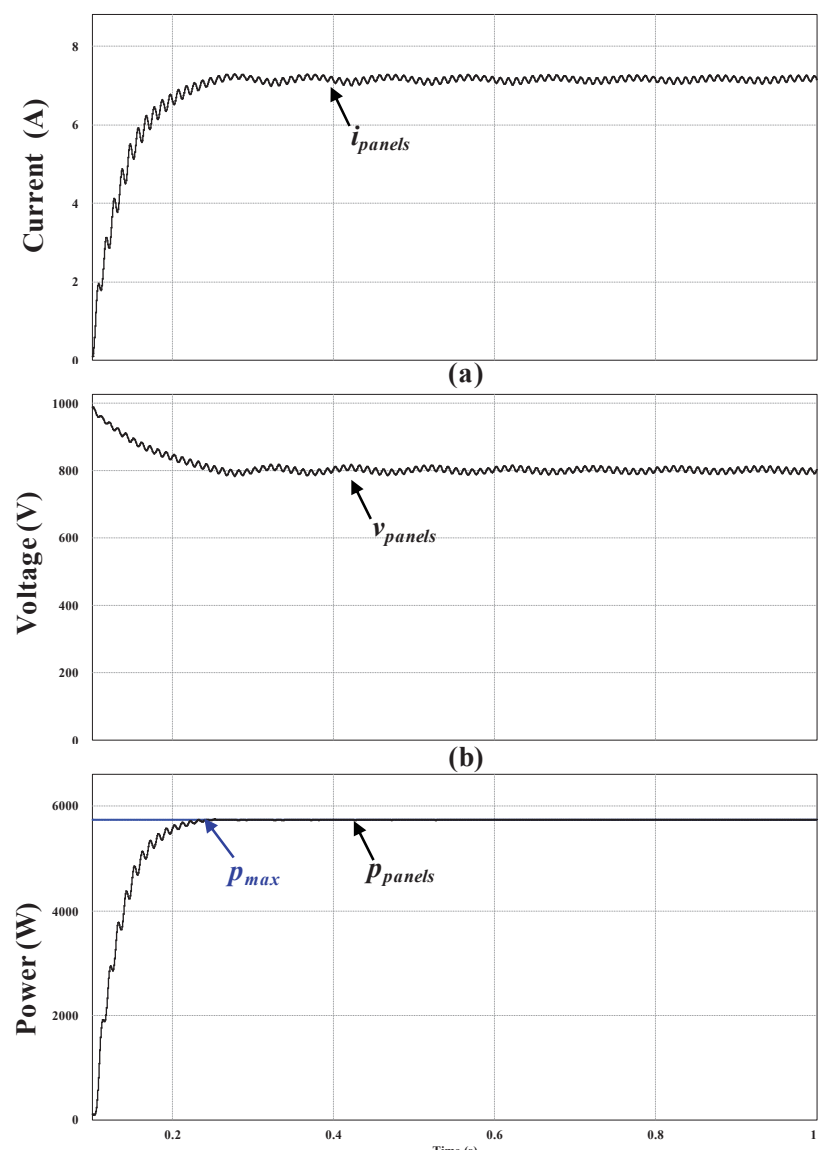

(c)

Figure 5. Startup of the proposed system with maximum solar radiation: (a) PV current $\left(i_{\text {panels }}\right)$; (b) PV panels voltage $\left(v_{\text {panels }}\right)$; (c) PV panels power $\left(p_{\text {panels }}\right)$. 
power of the solar panels array during the startup of the proposed system, with a maximum solar radiation of $1000 \mathrm{~W} / \mathrm{m}^{2}$. It can be seen that the power of the solar panels grows steadily without a significant ripple.

The current from the panels also increases in a controlled way. The system output power grows from zero to the maximum power in $0.25 \mathrm{~s}$. The voltage in the solar panels array decreases until reaching the point of maximum power. The current extracted from the panels is stable with a ripple of $7 \%$. The extracted power follows the maximum theoretical power of the system and has an average value of $5746 \mathrm{~W}$.

It was intended to test the behavior of the system when a fluctuation in the solar radiation occurs. For that it was made a simulation in which it was imposed a fluctuation by levels on the solar radiation from the maximum power of $1000 \mathrm{~W} / \mathrm{m}^{2}$ to $600 \mathrm{~W} / \mathrm{m}^{2}$, passing through a value of $800 \mathrm{~W} / \mathrm{m}^{2}$, as shown in Fig.6. It can be seen that the extracted power follows the maximum available power, this way validating the MPPT algorithm.

The peak value of the current injected into the power grid is 35 A. Fig. 7 shows the waveform of the inverter output current $\left(i_{\text {out }}\right)$ following the reference $\left(i_{\text {ref }}{ }^{*}\right)$. It can also be seen in Fig.8 that the power factor is unitary.

Fig.9 shows the regulated voltages at the DC-link capacitors,

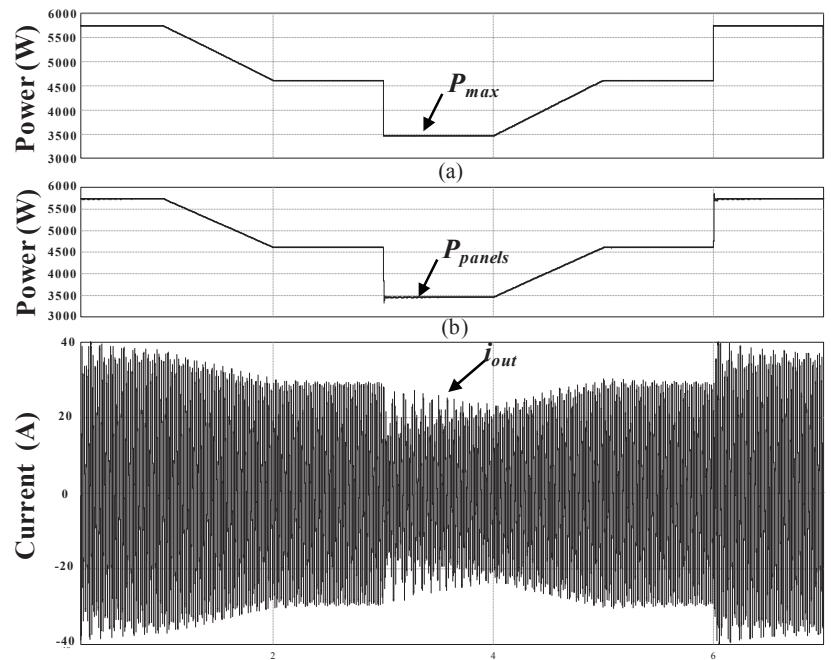

Times)

Figure 6. Operation with fluctuations in the solar radiation, from $1000 \mathrm{~W} / \mathrm{m}^{2}$ to $800 \mathrm{~W} / \mathrm{m}^{2}$ and to $600 \mathrm{~W} / \mathrm{m}$ : (a) Maximum theoretical power $\left(p_{\max }\right)$; (b) Extracted power PV panels $\left(p_{\text {panels }}\right)$; $(\mathrm{c})$ Inverter output current $\left(i_{\text {out }}\right)$.

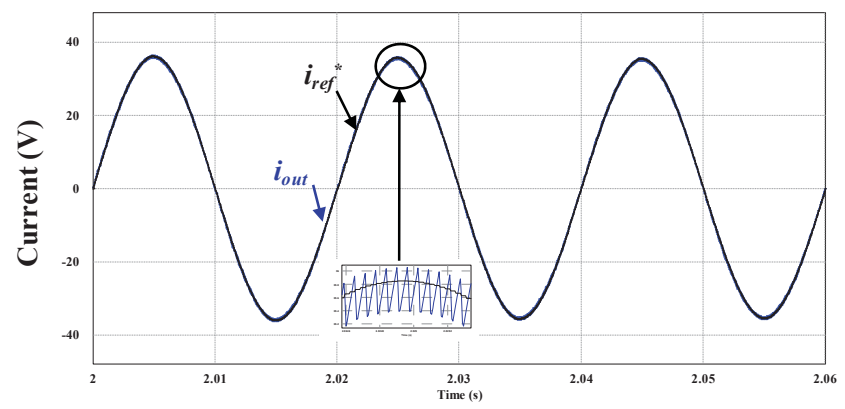

Figure 7. Reference current $\left(i_{r e f}{ }^{*}\right)$ and current injected into the power grid $\left(i_{\text {out }}\right)$.

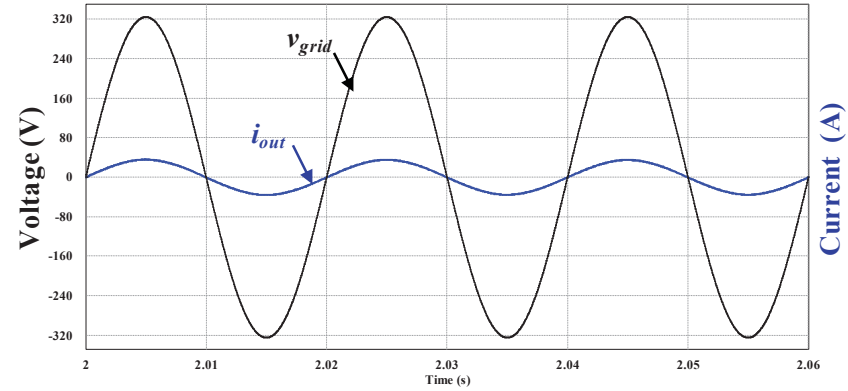

Figure 8. Power grid voltage $\left(v_{\text {grid }}\right)$ and inverter output current $\left(i_{\text {out }}\right)$.

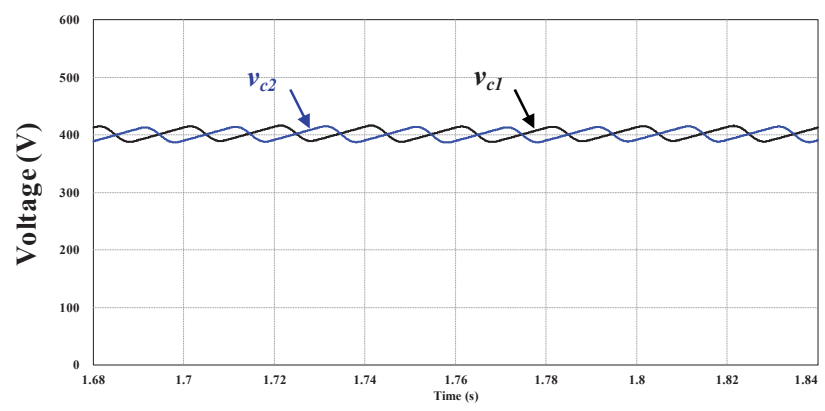

Figure 9. Voltages in the two capacitors of the DC-link $\left(v_{c l}, v_{c 2}\right)$. with a ripple of $15 \%$.

\section{EXPERIMENTAL RESULTS}

The control strategy previously discussed in this paper has been implemented and tested experimentally on a single phase NPC grid connected inverter. The inverter parameters are equal to the parameters of the simulation. The IGBTs used were the SKM50GB063D from SEMIKRON. In the implementation of the digital control was used a floating-point 32 bits DSP (TMS320F28335 from Texas Instruments). Fig. 10 shows the NPC inverter hardware set-up. Simulation results are presented at nominal voltage of $800 \mathrm{~V}$ DC and experimental results provided at a nominal voltage of $61.95 \mathrm{~V} \mathrm{dc}$ as shown in the table III, built in the laboratory.

All the experimental results that will be presented were measured using a Yokogawa DL708E oscilloscope. We first considered the implementation of the (PLL). Then, the implementation of the NPC inverter output current control.

Using an oscilloscope probe with a scale factor of (1/100), it can be seen in Fig. 11 the output signal generated by the

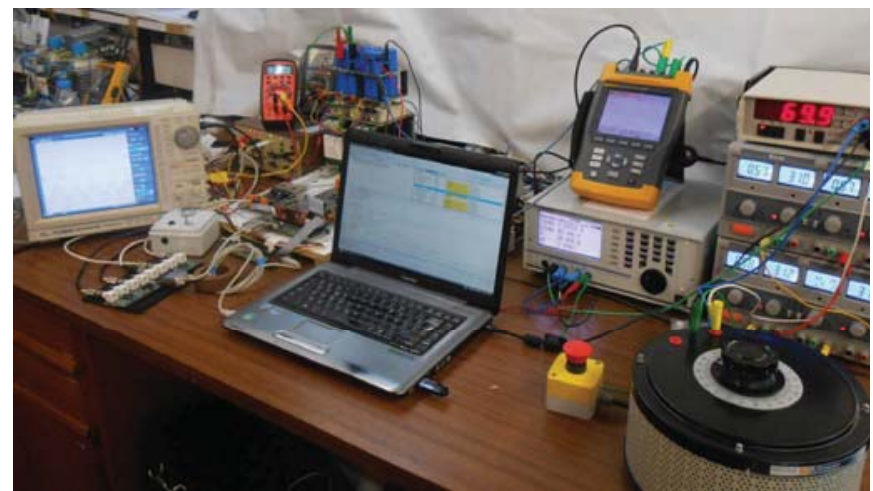

Figure 10. General view of the developed hardware setup. 
TABLE III. MAXIMUM POWER EXTRACTED AND INVERTER OUTPUT CURRENT WITH MPPT IMPLEMENTATION

\begin{tabular}{|c|c|c|c|c|}
\hline $\begin{array}{c}\text { Voltage } \\
(\mathbf{V})\end{array}$ & $\begin{array}{c}\text { Resistance } \\
(\boldsymbol{\Omega})\end{array}$ & $\begin{array}{c}\text { Maximum } \\
\text { theoretical } \\
\text { power(W) }\end{array}$ & $\begin{array}{c}\text { Measured } \\
\text { power (W) }\end{array}$ & $\begin{array}{c}\text { Output } \\
\text { measured } \\
\text { current(A) }\end{array}$ \\
\hline \multirow{3}{*}{61.95} & 100 & 9.59 & 9.58 & 2.2 \\
\cline { 2 - 5 } & 80 & 11.99 & 12.00 & 2.6 \\
\cline { 2 - 5 } & 60 & 15.99 & 16.53 & 3 \\
\cline { 2 - 5 } & 40 & 23.98 & 22.27 & 3.67 \\
\hline
\end{tabular}

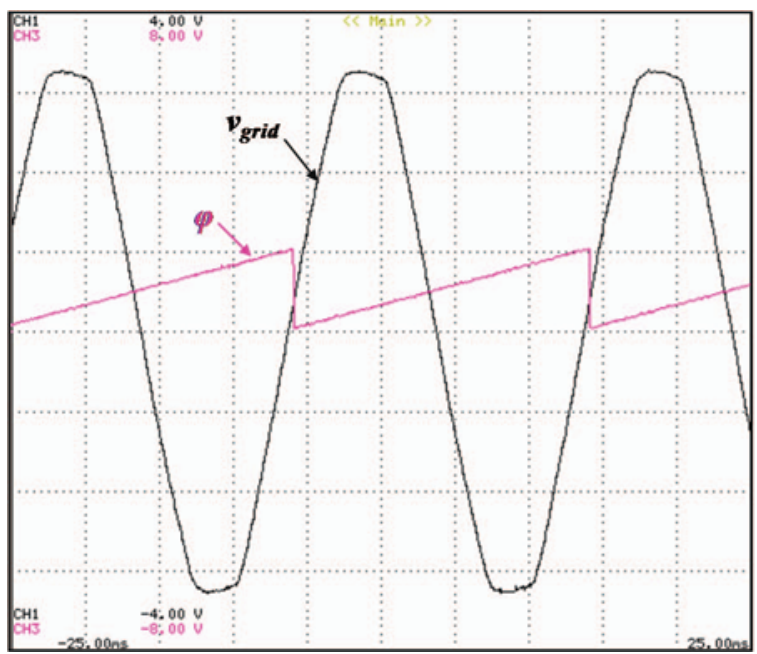

Figure 11. Power grid voltage $\left(v_{\text {grid }}\right)(100 \mathrm{~V} /$ div $)$ and phase generated by the PLL $(\varphi)$ $(6.28 \mathrm{~V} / \mathrm{div})$

oscillator controller $(\varphi)$, has the same phase and frequency of the power grid voltage $\left(v_{\text {grid }}\right)$, assuming values between 0 and $2 \pi$.

In Fig.12 is shown the output signal of the PLL $\left(v_{P L L}\right)$ devided by the amplitude $V_{\text {grid }}$ which is synchronized with the input signal $\left(v_{\text {grid }}\right)$.

After the validation of the PLL algorithm the output current

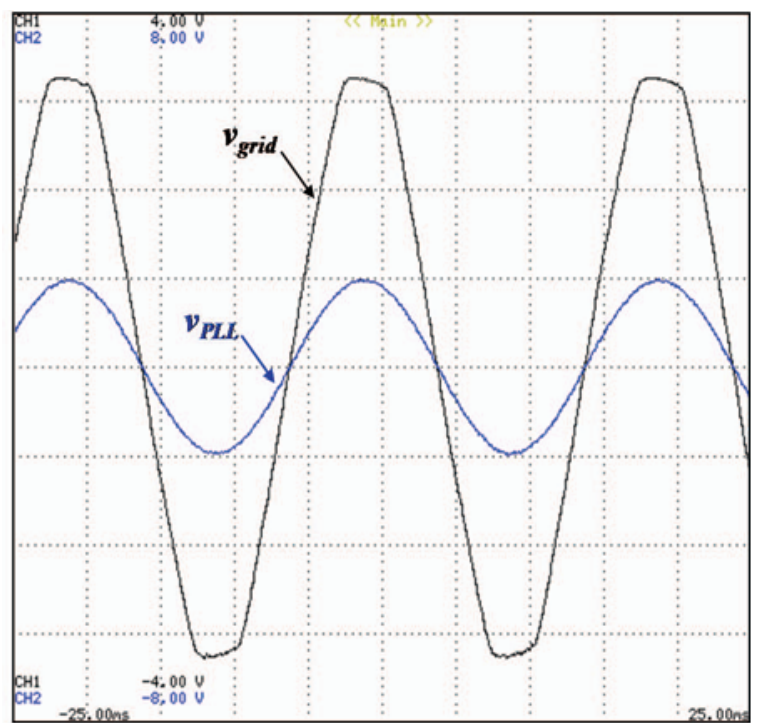

Figure 12. Power grid voltage $\left(v_{\text {grid }}\right)(100 \mathrm{~V} /$ div $)$ and PLL output signal $\left(v_{P L L}\right)$ $(1 \mathrm{~V} / \mathrm{div})$ and DC-link controls were validated. The voltages of the two DC-link capacitors are balanced as expected and the THD of the output current is equal to $2.2 \%$ as it is shown in Fig.13.

To validate the proper operation of the MPPT control algorithm, an ideal DC voltage source was used in series with a variable resistor to simulate a non ideal voltage source in order to change the maximum power supplied. The maximum power point occurs when the equivalent resistance of the NPC inverter is equal to the rheostat resistance (this operation assume the matching power), or to supply the inverter is seen as an equivalent resistance.

Fig.14 shows the maximum power extracted for a given input voltage of $60 \mathrm{~V}$ and different value of rheostat resistance.

Table III shows the maximum power extracted which is measured by a digital power meter ISW8000 and the output current of the NPC inverter depending on the resistance value of the rheostat.

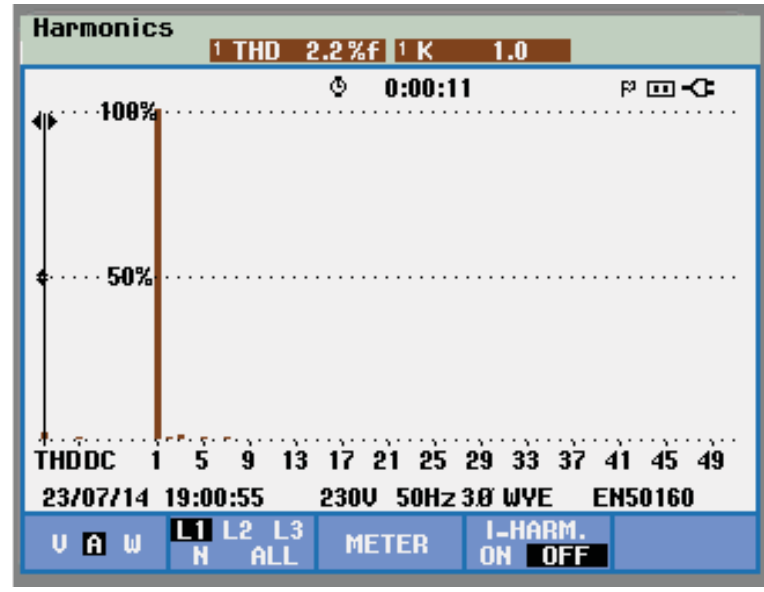

Figure 13.Total Harmonic Distorsion of the output current current

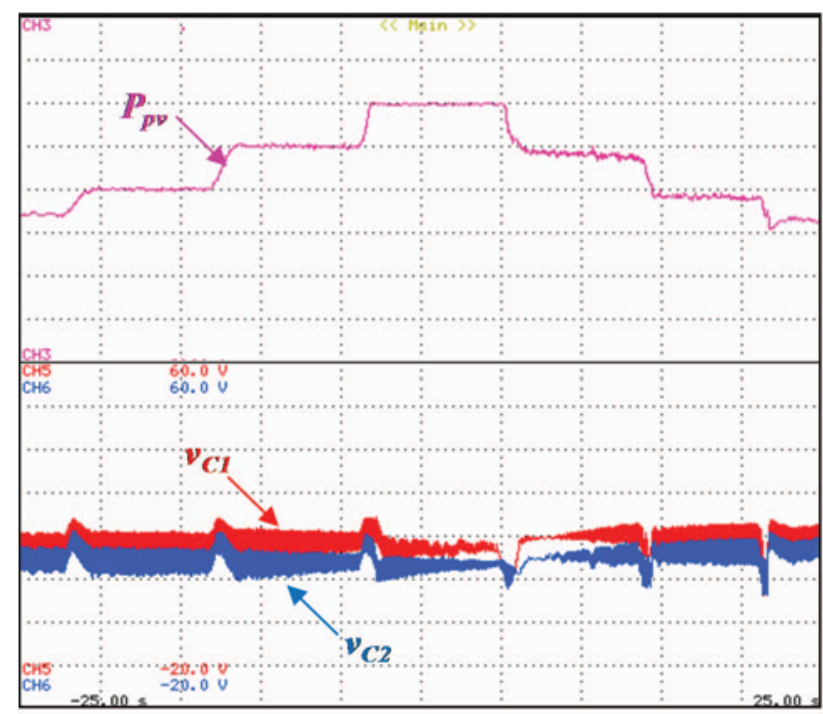

Figure 14. Maximum power extracted from the non ideal voltage source $\left(P_{p v}\right)$ $(3.8 \mathrm{~W} / \mathrm{div})$ and voltages in the two capacitors of the DC-link $\left(v_{C l}, v_{C 2}\right)$ $(10 \mathrm{~V} /$ div $)$ 
From fig.15, fig.16, fig.17 and fig.18 we can remark that the output current follow exactly the reference current imposed by the control strategy.

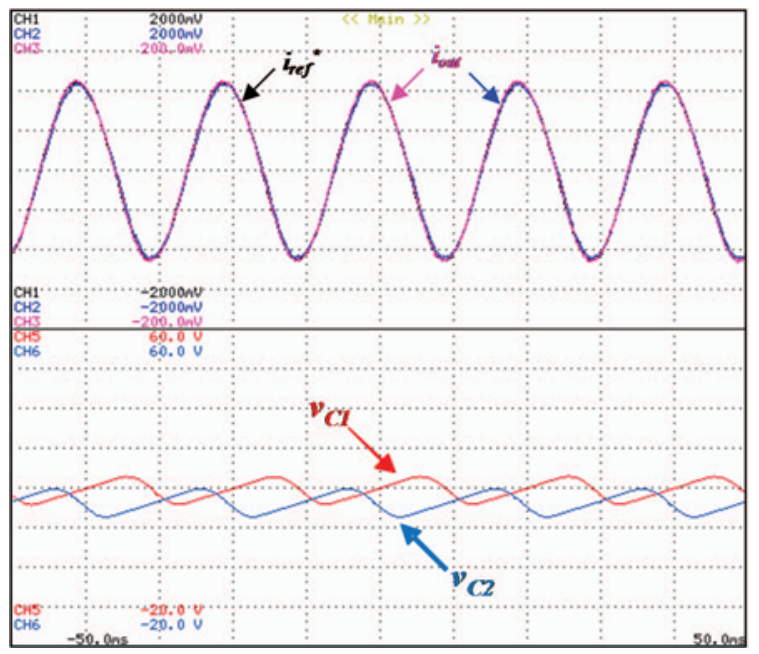

Figure 15. output current $\left(\mathrm{i}_{\text {out }}\right)$, reference curent $(1 \mathrm{~A} / \mathrm{div})$ and voltages in the two capacitors of the DC-link $\left(v_{C 1}, v_{C 2}\right)(10 \mathrm{~V} / \mathrm{div})$ for $\mathrm{R}=100 \Omega$

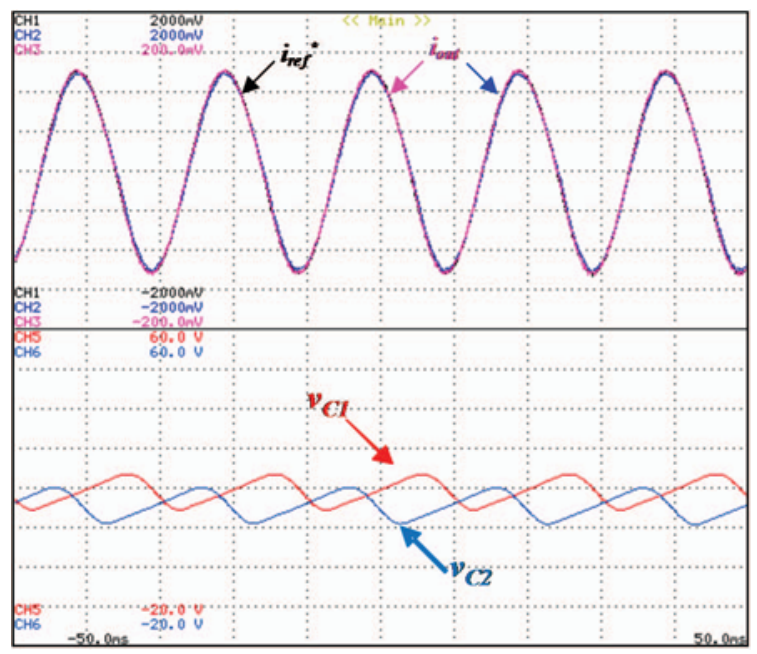

Figure 16. output current $\left(\mathrm{i}_{\text {out }}\right)$, reference current $(1 \mathrm{~A} / \mathrm{div})$ and voltages in the two capacitors of the DC-link $\left(v_{C 1}, v_{C 2}\right)(10 \mathrm{~V} / \mathrm{div})$ for $\mathrm{R}=80 \Omega$.

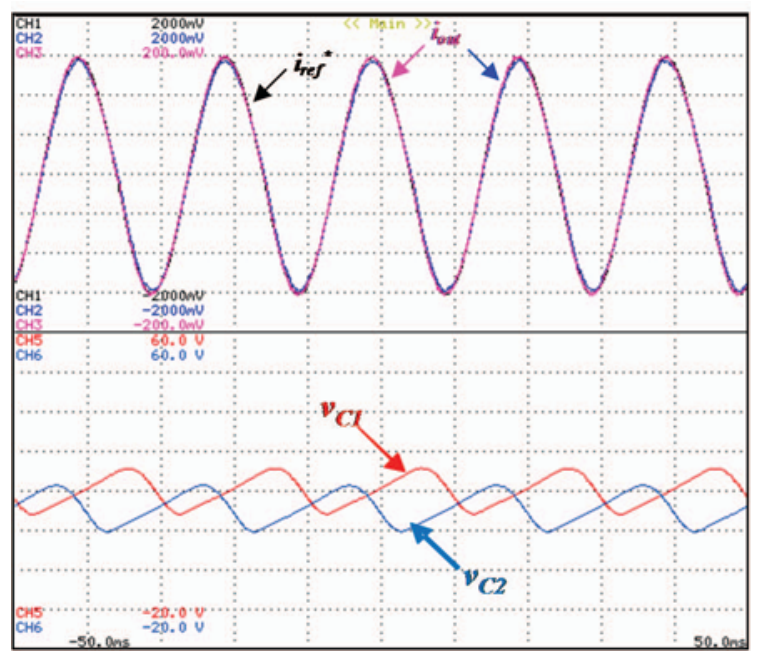

Figure 17. output current $\left(\mathrm{i}_{\text {out }}\right)$, reference current $(1 \mathrm{~A} / \mathrm{div})$ and voltages in the two capacitors of the DC-link $\left(v_{C 1}, v_{C 2}\right)(10 \mathrm{~V} / \mathrm{div})$ for $\mathrm{R}=60 \Omega$.

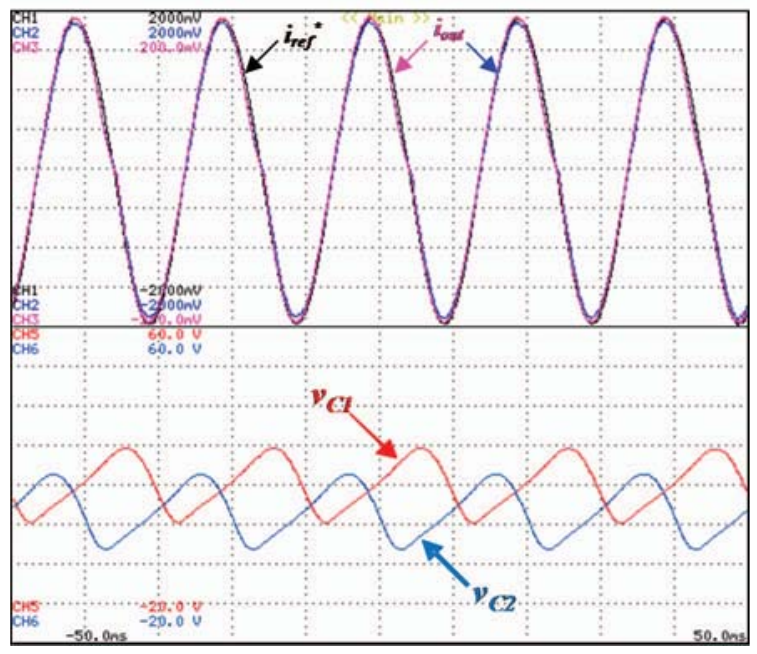

Figure 18. output current $\left(\mathrm{i}_{\text {out }}\right)$, reference current $(1 \mathrm{~A} / \mathrm{div})$ and voltages in the two capacitors of the DC-link $\left(v_{C 1}, v_{C 2}\right)(10 \mathrm{~V} / \mathrm{div})$ for $\mathrm{R}=40 \Omega$.

The inverter output current was obtained through a current probe connected to the oscilloscope with a transformation ratio of $10 \mathrm{mV} / \mathrm{A}$. However, for a better resolution were given 5 turns on the wire around the current probe.

\section{CONCLUSION}

This paper presents the design, simulation and experimental results of a $5 \mathrm{~kW}$ single-stage three-level Neutral Point Clamped (NPC) inverter for connection to the electrical power grid, with integrated Maximum Power Point Tracking (MPPT) algorithm to extract the maximum available power from solar photovoltaic (PV) panels. It also describes the design of the PLL controller, used to track the fundamental power grid voltage in order to synchronize the NPC inverter with the power grid, and to generate a reference for the inverter output current (which consists in the injected power grid current). All the controllers have been implemented using $\mathrm{C}$ code, validated by simulation in PSIM, and executed in a DSP. Experimental results indicate that the current injected in the power grid follows the reference, and that the voltages in the two DC-link capacitors are kept balanced. It is shown that the proposed system is able to always extract the maximum power available from the solar PV panels, even when there are solar radiation fluctuations.

\section{REFERENCES}

[1] S. V. Araújo, S. Member, P. Zacharias, and R. Mallwitz, "Highly Efficient Single-Phase Transformerless Inverters for Grid-Connected Photovoltaic Systems," Ind. Electron. IEEE Trans., vol. 57, no. 9, pp. 3118-3128, 2010.

[2] S. Saridakis, E. Koutroulis, and F. Blaabjerg, "Optimal Design of Modern Transformerless PV Inverter Topologies," Energy Conversion, IEEE Trans., vol. 28, no. 2, pp. 394-404, 2013.

[3] R.Teodorescu, M.Liserre, and P.Rodriguez, Grid Converters for Photovoltaic and Wind Power Systems. 2011.

[4] S. Busquets-monge, J. Rocabert, P. Rodríguez, P. Alepuz, and J. Bordonau, "Multilevel Diode-Clamped Converter for Photovoltaic Generators With Independent Voltage Control of 
Each Solar Array," Ind. Electron. IEEE Trans., vol. 55, no. 7, pp. 2713-2723, 2008.

[5] P. Panagis, F. Stergiopoulos, P. Marabeas, and S. Manias, "Comparison of State of the Art Multilevel Inverters," Power Electron. Spec. Conf. 2008. PESC 2008. IEEE, pp. 42964301, 2008

[6] R. Stala, "Application of Balancing Circuit for DC-Link Voltages Balance in a Single-Phase Diode-Clamped Inverter With Two Three-Level Legs," IEEE Trans. Ind. Electron., vol. 58, no. 9, pp. 4185-4195, Sep. 2011.

[7] H. Sun, M. Park, J. Park, H. Kim, T. Chun, and E. Nho, "Novel H-bridge Multi-level Inverter with DC-link Switches," in Power Electronics and ECCE Asia (ICPE ECCE), 2011 IEEE 8th International Conference on, 2011, pp. 1734-1741.

[8] S. Golestan, M. Monfared, F. D. Freijedo, and J. M. Guerrero, "Advantages and Challenges of a Type-3 PLL," IEEE Trans. Power Electron., vol. 28, no. 11, pp. 4985-4997, 2013.

[9] B. A. A. Antao, F. M. El-turky, and R. H. Leonowich, "Behavioral Modeling Phase-locked Loops for Mixed-Mode Simulation," Analog Integr. Circuits Signal Process., no. 10, pp. 46-65, 1996.

[10] M. Karimi, M. R. Iravani, and F. Katiraei, "Extraction of signals for harmonics, reactive current and networkunbalance compensation," Gener. Transm. Distrib. IEE Proceedings-, vol. 152, no. 1, pp. 137-143, 2005.

[11] M. Karimi, "Linear and Pseudolinear Enhanced PhasedLocked Loop (EPLL) Structures," Ind. Electron. IEEE Trans., vol. 61, no. 3, pp. 1464-1474, 2014.

[12] L. M. Elobaid, A. K. Abdelsalam, and E. E. Zakzouk, "Artificial Neural Network Based Maximum Power Point Tracking Technique for PV Systems," IECON 2012 - 38th Annu. Conf. IEEE Ind. Electron. Soc., pp. 937-942, 2012.

[13] A. Reza Reisi, M. Hassan Moradi, and S. Jamasb, "Classification and comparison of maximum power point tracking techniques for photovoltaic system: A review," Renew. Sustain. Energy Rev., vol. 19, pp. 433-443, Mar. 2013.

[14] H.-T. Yau, Q.-C. Liang, and C.-T. Hsieh, "Maximum power point tracking and optimal Li-ion battery charging control for photovoltaic charging system," Comput. Math. with Appl., vol. 64, no. 5, pp. 822-832, Sep. 2012.

[15] S. R. Nelatury, "A maximum power point algorithm using the Lagrange method," J. Power Sources, vol. 234, pp. 119-128, Jul. 2013.

[16] T. Bennett, A. Zilouchian, and R. Messenger, "Perturb and Observe versus Incremental Conductance MPPT Algorithms," IEEE Trans. POWER Syst., pp. 1-9.

[17] K. Visweswara, "An Investigation Of Incremental Conductance Based Maximum Power Point Tracking For Photovoltaic System," Energy Procedia, vol. 54, pp. 11-20, 2014.

[18] S. Z. Mirbagheri, S. Mekhilef, and S. M. Mirhassani, "MPPT with Inc . Cond method using conventional interleaved boost converter," Energy Procedia, vol. 42, pp. 24-32, 2013.

[19] T. Esram and P. L. Chapman, "Comparison of Photovoltaic Array Maximum Power Point Tracking Techniques," vol. 22, no. 2, pp. 439-449, 2007.

[20] L. A. SERPA, "Current Control Strategies for Multilevel Grid Connected Inverters," no. 17463, 2007.

[21] R. Teodorescu and F. Blaabjerg, "Proportional-resonant controllers. A new breed of controllers suitable for gridconnected voltage-source converters," pp. 1-6, 2004. 